BMJ Paediatrics Open

\title{
Pet dog bites in children: management and prevention
}

\author{
Molly Jakeman, ${ }^{1}$ James A Oxley ${ }^{2}$ Sara C Owczarczak-Garstecka, ${ }^{2,3}$ \\ Carri Westgarth (iD ${ }^{2}$
}

To cite: Jakeman M, Oxley JA, Owczarczak-Garstecka SC, et al. Pet dog bites in children: management and prevention. BMJ Paediatrics Open 2020;4:e000726. doi:10.1136/ bmjpo-2020-000726

Received 4 May 2020

Revised 25 June 2020

Accepted 29 June 2020
Check for updates

(c) Author(s) (or their employer(s)) 2020. Re-use permitted under CC BY-NC. No commercial re-use. See rights and permissions. Published by BMJ.

${ }^{1}$ Department of Plastic Surgery, Alder Hey Children's NHS Foundation Trust, Liverpool, UK ${ }^{2}$ Faculty of Health and Life Sciences, Department of Livestock and One Health, University of Liverpool, Liverpool, UK

${ }^{3}$ Dogs Trust, London, UK

Correspondence to Dr Carri Westgarth; Carri. Westgarth@liverpool.ac.uk

\section{ABSTRACT}

Dog bite injuries are a significant public health problem and many are sustained by children. These injuries can be complex, both physically and psychologically, and in rare cases fatal. This paper will review current evidencebased approaches to treatment, explore identified patterns in biting incidents and discuss the effectiveness of prevention strategies. Safe management of these patients requires a comprehensive approach. Physical injuries need to be accurately assessed with a high index of suspicion for underlying injuries, particularly in younger children less able to communicate. Treatment depends on severity and location, but all bites must be irrigated to reduce the risk of infection but may not always require prophylactic antibiotic use. Careful exploration of the circumstances in which the bite occurred is essential to make safeguarding decisions and prevent future bites. Reducing the incidence of paediatric dog bites requires education of both children and parents that any dog can bite, regardless of breed, and all child-dog interactions must be highly supervised. However, education alone is unlikely to prevent dog bites. Policies that support environmental changes need to be developed such as provision of pet dogs less likely to bite (or bite as severely), through breeding for temperament and appropriate socialisation. Additionally, investment in psychological support for bite victims and their families is required to reduce the long-term impacts of being bitten.

\section{INTRODUCTION}

There are an estimated 700 million dogs worldwide and tens of millions of people are injured by dogs each year. ${ }^{12}$ There are nine million dogs in the UK with $25 \%$ of households owning a domestic dog. ${ }^{3}$ Between financial years ending 2014 and 2018, the number of hospital admissions for 'dog bites and strikes' (which will now be referred to as ' $\mathrm{dog}$ bites') rose by $17 \%$ to over 8000 per year in England. ${ }^{4}$ In the USA, dog bites account for an average of 337103 emergency visits per year. ${ }^{5}$ Lowincome countries are estimated to have a higher incidence of bites and resulting fatalities than high-income countries due to the prevalence of rabies and the relative lack of access to appropriate healthcare. ${ }^{2}$ This

\section{Key messages}

- A thorough history can reveal patterns of injury, highlight safeguarding concerns, guide medical management in addition to informing preventative measures.

- The psychological impact of a dog bite on both the child and carer is often overlooked.

- The majority of paediatric dog bites occur in the home.

- A multidisciplinary approach is required to develop more comprehensive and effective prevention schemes.

review focuses on the dog bite management and prevention in high-income and middleincome countries, but may also have relevance in other contexts.

Bites from dogs account for nearly $70 \%$ of all hospital admissions for mammalian bites costing the NHS an estimated $£ 10$ million per year. ${ }^{67}$ There is significant regional variation in rates of hospitalisation for dog bites. In England, higher rates are seen in more deprived areas (as measured by the Index of Multiple Deprivation), with the highest rate reported in Merseyside (27.0 per 100000 population) ${ }^{6}$ Children are more likely than adults to receive medical attention for these injuries. ${ }^{8}$ Those under the age of 9 years are disproportionately affected (17.6 per 100000 population) and account for twothirds of admissions among < 18 year olds. ${ }^{6}$ Specifically, research has identified two age groups of children that are bitten most often: those under the age of 2 years, ${ }^{9-11}$ and those aged $9-12 .^{9} 12$ The true incidence of dog bites is likely to be underestimated as studies have found that only a third of dog bite victims seek medical treatment and of those that do, not all will receive treatment in a hospital setting and therefore would not be included in the above figures. ${ }^{13} 14$ In addition to physical impact, dog bites often carry psychological costs to the victim and their guardians, ${ }^{15-18}$ which is understudied. 


\section{PHYSICAL ASSESSMENT AND MANAGEMENT}

\section{History and examination}

Paediatric dog bite injuries can be life-threatening or limb-threatening, due to internal organ injury, ischaemic insult or bacterial contamination. ${ }^{19}$ Therefore, the initial assessment of a paediatric dog bite victim follows the same approach as that of a trauma patient. ${ }^{20}$ Once the patient is stabilised, an in-depth assessment of the dog bite can be performed. An accurate history of the incident can reveal information regarding the pattern of trauma, highlight safeguarding concerns and inform the risk assessment for both tetanus and rabies (if not in a rabies-free area). Accurate and thorough documentation regarding the circumstances of the injury is also essential to aide research in this area, which can inform bite prevention schemes.

Details regarding the circumstance of the bite should be noted by asking for descriptions (rather than interpretations) of the dog and child behaviours before and during the event. Labels based on presumed motivations of dog behaviour such as 'jealously' or 'territorial' should be avoided. Information regarding dog breed, sex and neuter status, if known, should be collected (however, please see the discussion later for limits of breed-related inference). The general health of the dog should be noted, as painful medical conditions or illness can contribute to aggressive behaviour. ${ }^{21}$ Dogs may show pain-induced aggression which may not easily be recognised by the caregiver, highlighting the importance of regular professional veterinary assessments even if the dog is perceived to be healthy. In addition, any previous instances of aggression and nervousness should be enquired about, as a history of aggressive behaviour is a risk factor for future bites. ${ }^{22}{ }^{23}$ In cases where there is a known history of aggressive behaviour, it must be strongly advised that a veterinary surgeon who specialises in behaviour, or other expert behaviourist, should be consulted.

In the paediatric population, identifying safeguarding concerns is essential. The National Institute of Healthcare Excellence (NICE) advises that a dog bite to a child in the context of inadequate supervision should raise suspicion of neglect. ${ }^{24}$ However, the understanding of adequate supervision around dogs is not universal and ways of improving caregivers' supervision skills are unclear (see the Prevention section for a discussion of parental supervision). Therefore, evaluation of the context in which the child was injured, the circumstances in which the child encounters the dog and the history of both dog behaviour and caregivers' supervision practices will inform the assessment of ongoing risk to the child. This assessment is of particular importance when the dog is owned by the family or is frequently in close proximity to the child.

Knowledge of the circumstances of the injury, in addition to the size of the dog relative to the child, can provide insight into the expected pattern of injury. A 'snap and release' mechanism results in puncture-type wounds whereas a 'grip and retain' mechanism can lead to a spectrum of injury, from simple lacerations to soft tissue loss, with or without significant structural or internal organ injury. ${ }^{25}$ The medical status of the victim should be noted with special attention given to risk factors for developing sepsis, including those who are immunocompromised or asplenic. ${ }^{26}$ Evaluation of the injuries should include the anatomical location, type and depth of the wounds. An assessment for underlying structural involvement, including the neurovascular status distal to the injury, should be noted. Wounds should be evaluated for the extent of devitalised tissue, signs of infection or foreign material. Underlying bone fractures have been identified in dog bite cases as frequently as $7.7 \% .{ }^{27}$ Therefore, plain film radiographs should be performed when an underlying fracture is suspected, when the wound is overlying a joint and to exclude deep radio-opaque foreign bodies, such as teeth. ${ }^{2829}$

\section{Medical interventions}

A risk assessment for tetanus and rabies should be performed. At present, the UK is considered a "no risk' country for the contraction of rabies from a dog. ${ }^{30}$ However, this status is currently under threat from importation of dogs without valid vaccinations. ${ }^{31}$ Bites acquired elsewhere should be risk assessed and where indicated, postexposure treatment administered according to Public Health England (PHE) guidance. ${ }^{30}$ PHE advises that wounds with extensive tissue devitalisation or heavy contamination with soil or agricultural material should be considered high risk for tetanus. However, no immediate further treatment for tetanus risk is required in:

- Patients aged 11 years and over, who have received an adequate priming course (three doses given 1 month apart) of tetanus vaccine with the last dose within 10 years.

- Patients aged 5-10 years who have received priming course and preschool booster.

- Patients under 5 years who have received an adequate priming course. ${ }^{32}$

These patients should be advised to complete the immunisation schedule as normal. For those with an incomplete vaccination history for their age, tetanus toxoid with or without tetanus immunoglobulin should be administered, according to the assessed level of risk.

NICE recommends antibiotic prophylaxis for puncture wounds, bite injuries to the hands, feet, face or genitalia, immunocompromised patients and those requiring surgery or with an underlying structural injury. ${ }^{28}$ Further recommendations include provision of antibiotics for all bite wounds presenting 8 hours or more after injury. ${ }^{28}$ However, antibiotic use for wounds presenting after 48 hours with no signs of infection is not indicated due to limited benefit in this context. ${ }^{25}$ These recommendations are based largely on expert opinion, with the exception of bites to the hand, which are supported by a Cochrane review. ${ }^{33}$ Common pathogens found in infected dog bite wounds include Pasturella, Staphlococcus and Streptococcus 
species and therefore broad-spectrum antibiotic cover, such as co-amoxiclav, for 1 week is recommended. ${ }^{28}{ }^{29}$ For penicillin-allergic patients under 12 years of age, advice should be sought from a microbiologist. ${ }^{28}$ Bites in patients with signs of systemic infection should be managed according to local sepsis protocols, ensuring that wound and blood cultures are taken to help guide antimicrobial therapies.

\section{Wound management}

Irrigation of all bite wounds should be performed to help prevent infection. Irrigation under pressure is not recommended due to the risk of spreading bacteria into deeper tissue. ${ }^{28}$ There is no evidence to support the use of sterile water over warm tap water, and the latter is recommended for first aid measures. ${ }^{28}$ The wound should be encouraged to bleed slightly to aid expelling any foreign material or contaminant. Debridement of all devitalised tissue and removal of any remaining foreign material should be performed. $^{28}$

Primary closure of bite wounds is a controversial issue. With adequate irrigation, infection rates for primary closure and non-delayed or delayed closure in simple wounds presenting early are similar. ${ }^{28} 34$ In general, wounds presenting 24 hours or later postinjury, those that are clinically infected or puncture wounds without structural injury, should be allowed to heal by secondary intention. ${ }^{28}$ Special consideration of primary closure should be given to wounds in cosmetically sensitive areas as this may provide the best aesthetic outcome. ${ }^{35}$ Simple lacerations can be closed in the emergency department with local anaesthetic with or without sedation, if local policies allow and the child can tolerate it. However, complex lacerations or children who cannot tolerate intervention under sedation should be referred for debridement and operative repair. Wounds with tissue loss or underlying structural injuries, including fractures, should be referred onto the appropriate surgical team for further management. The need for reconstructive surgery in the form of skin grafts or flaps has been reported in up to $5.1 \%$ of cases. ${ }^{27}$ Puncture wounds or wounds with signs of localised infection should be given antibiotics and reviewed again within 48 hours. ${ }^{28}$ Follow-up for wounds managed operatively depends on the site, size, intervention undertaken and the anticipated risk of infection.

\section{PSYCHOLOGICAL IMPACTS}

The psychological impact of dog bites is often poorly documented and therefore poorly reported. Studies have demonstrated a spectrum of psychological disturbance in children following a dog bite from avoidance behaviours to formal diagnosis of post-traumatic stress disorder (PTSD).${ }^{16}$ Boat et al ${ }^{15}$ found that in more than $70 \%$ of $\operatorname{dog}$ bite cases, parents reported at least one new concerning behaviour. Nearly a third of children demonstrated a new fear or avoidance of dogs and one-fifth experienced nightmares following the incident. Ji et $a l^{16}$ found an incidence of $5 \%$ of PTSD at 3 months postinjury. PTSD symptoms can be varied and range from avoidance behaviours and numbing to increased arousal, hypervigilance and vivid recollections. ${ }^{36}$ These distressing symptoms can be experienced in isolation thereby not meeting the criteria for a diagnosis of acute stress disorder (ASD) or PTSD and may go unrecognised. ${ }^{16}$

The psychological impact is seen in both children treated in the emergency department and those requiring admission. ${ }^{16}$ However, both ASD and PTSD appear to occur more commonly in children who require hospitalisation for their injuries. ${ }^{16}$ Further research is required to determine whether this is simply a reflection of the severity of injury or whether inpatient intervention itself is a contributory factor.

The psychological impact can persist for many months following the incident. Peters $\mathrm{et}^{1 l^{7}}$ found that in a cohort of 22 children all treated in the emergency department setting, 12 had reported PTSD symptoms for more than 1 month when interviewed at a median interval of 7 months post-injury.

It is also important to note that there is a psychological impact on the carers of paediatric victims. Boat $e t$ $a l^{15}$ found that $85 \%$ of parents whose child sustained a dog bite injury reported changes in their own feelings following the incident. Two-thirds reported feelings of guilt and just under half reported feeling angry or fearful for their child's safety.

Caregivers of a child involved in a traumatic event should be informed of the normal responses to trauma (symptoms such as nightmares, avoidance behaviour, increased behavioural difficulties) and advised to contact their general practitioner if these symptoms persist past 1 month. ${ }^{37}$ Given the diverse presentations of psychological disturbance following trauma, in both adults and children, and the complex emotions surrounding seeking help, a more proactive approach to screening and referral for psychological input would seem appropriate. However, this approach is limited by the low quality and limited evidence for early intervention to prevent the development of PTSD. ${ }^{37}$

\section{RISK FACTORS AND BITE CIRCUMSTANCES}

There is an increasing body of evidence regarding the patterns and potential risk factors of paediatric dog bites which is being used to inform prevention schemes (see box 1). However, this is limited due to patient's failing to seek medical attention and insufficient clinical documentation of the bite circumstances. ${ }^{10}$ Children aged $<5$ are most likely to present with injuries to the head and neck. ${ }^{527}$ This is thought to be a result of a number of factors including the child's height and tendency to crawl or play on the floor. ${ }^{27}$ In particular, children aged $<2$ tend to place their face in close proximity to new or moving objects which may trigger a reaction from a dog. ${ }^{38}$ Children aged $>9$ are more likely to sustain injuries to their extremities, presumably due to their increased height 


\section{Box 1 Patterns in paediatric dog bites}

Children under the age of 2 years and between the ages of 9 and 12 years are most commonly bitten.

- Children under 5 years are more likely to be bitten in the head or neck.

Boys are more likely to be bitten.

- Children are most commonly bitten in the home.

The dog is owned by the family in the majority of cases.

- Paediatric dog bites tend to occur in the early evening or on the weekend, and are more common in the summer months.

and the limbs being the closest point to the animal during a bite. ${ }^{27}$ In most studies, boys are often reported to be more frequently bitten than girls, ${ }^{39-42}$ but not in all cases. ${ }^{43}$

In $70 \%$ of dog bite cases, the dog is owned by a family member and children are most commonly bitten in the home. ${ }^{510}$ Paediatric dog bites are common in the summer months and occur most frequently between 16:00 and 20:00 and on weekends. ${ }^{54}$ This may reflect times where children are more likely to be around dogs, potentially unsupervised, during food preparation or meal times. ${ }^{1044}$ Reisner et $a l^{45}$ reported that in $42 \%$ of cases where the dog was familiar with the child, the attributed cause for the bite was in response to food guarding. However, it is important to note that bites can occur in a number of contexts and in some cohorts, they most commonly occurred while interacting with the dog, including during play. ${ }^{13} 46-48$

Ability to correctly interpret dog behaviour improves with age and children aged $<7$ struggle to identify fearrelated behaviours in dogs. ${ }^{49}{ }^{50}$ However, even when able to correctly identify fear, young children do not know safe behaviours, commonly reporting they would approach fearful dogs, ${ }^{49}$ hence physical separation except when very closely supervised is paramount. Dogs with a fearful or nervous predisposition may be more likely to show aggressive behaviour towards children. For example, more than three quarters of dogs involved in bites to children were reported to have a history of fear-related behaviour in other contexts, such as in response to loud noises or separation from their owner. ${ }^{45}$ An increase in the number of dog bites at times of thunderstorms has also been reported. ${ }^{51}$ However, this may also reflect changes in human behaviour around dogs at this time, such as attempts to comfort the animal.

A systematic review found both limited and conflicting evidence to support specific breed, sex or age of the dog as risk factors for biting. ${ }^{23}$ In general, larger dogs may cause more severe injury from a bite compared with small dog due to the relative difference in size, however, research indicates that small dogs are at a higher risk of biting their owners. ${ }^{22}$ Identifying a link between bite risk and dog breeds is limited by the accuracy of breed identification by the victim. ${ }^{52}$ In addition, the public are more likely to report a breed when they believe they were bitten by a breed listed within the Dangerous Dogs Act (Pit Bull Terriers, Japanese Tosa, Dogo Argentino and Fila Brasileiro) than other breeds. ${ }^{52} 53$ Moreover, heterogeneity of dog breeds involved in bites means that studies are often under-powered to detect statistically significant differences in risk between breeds. ${ }^{22}$ The evidence for an effect of neutering on human-directed aggression is conflicting, and further longitudinal research is required to determine the causal direction. ${ }^{23}$ However, there is some evidence to suggest that human-directed aggression may have a heritable component, which is a potentially modifiable risk factor and warrants further investigation. $^{23} 54$

\section{DOG BITE PREVENTION}

Dog bites should be regarded as predictable and preventable unintentional injuries, rather than accidents. ${ }^{55}$ Unfortunately, perception of dog bites as "just one of those things' promotes a view that nothing can be done to prevent them. ${ }^{18}$ Preventing injuries as a result of dog bites is complex due to the number of factors involved (ie, the dog, the child, the environment, the parental supervision and the dog-child interaction). When considering child injury prevention, parent-child supervision and interventions to mitigate the risk of hazards are essential factors to consider. ${ }^{56}$

\section{Existing approaches to dog bite prevention}

Current dog bite prevention interventions take two forms-environmental management (eg, dog-related legislation) and education. ${ }^{57}$ In the UK, nationwide environmental management was implemented in the form of the Dangerous Dogs Act 1991, after several highly publicised dog attacks. This has been heavily criticised and thought to have had little impact on hospital admissions for dog bite injuries. ${ }^{453}$ In contrast, the City of Calgary, Canada, has seen a reduction in the frequency of dog bites frequency following the introduction of a compulsory dog licensing scheme and an introduction of subsidised dog training classes. ${ }^{58}$

\section{Prevention through education}

Most research in dog bite prevention is focused on prevention and safety education schemes aimed at children and caregivers. Recent research analysing online video content of dog bite incidents has identified that prior to a bite, dogs express anticipatory behavioural signals in accordance with the canine ladder of aggression approximately $20 \mathrm{~s}$ before a bite occurs, suggesting that there is some scope for intervention. ${ }^{48} 59$

Education interventions are available in many forms including books, websites, primary school teaching resources and posters. In the UK, there is currently a range of schemes that use knowledge of $\operatorname{dog}$ behaviour and identified risk factors to inform children and parents of safe behaviour around dogs, such as: 
- The Blue Dog Scheme (https://www.thebluedog. org/en/).

- Be Dog Smart (Dogs Trust) (https://www.learnwithdogstrust.ie/be-dog-smart/).

- Be Safe with Dogs (Blue Cross) (https://www.bluecross.org.uk/pet-advice/be-safe-dogs).

- The Safe and Sound Scheme (The Kennel Club) (https://www. thekennelclub.org.uk/training/ safe-and-sound/).

Of the limited research conducted on the effectiveness of dog bite prevention schemes (see review by Shen et al), ${ }^{575}$ there is evidence to support that educational schemes have the potential to increase knowledge of safe behaviours around a dog in the short term. ${ }^{60}$ However, they do not appear sufficient to change the behaviour of children in the presence of a real dog or the behaviour of parents in the presence of a dog not known to them. ${ }^{60} 61$ This is unsurprising given the known poor effectiveness of 'educational' approaches to injury prevention, ${ }^{62} 63$ which are often chosen due to a tendency to blame the victim for doing something wrong, ${ }^{64}$ as also perceived in dog bites. ${ }^{18}$ Even with knowledge, it is very hard for people to change their behaviour, and people will always make mistakes. ${ }^{60}{ }^{65}$ Further research is required to determine the most effective method for knowledge acquisition, retention and resulting behavioural changes, for all ages. Furthermore, there needs to be closer collaboration between medics, vets and public health professions to develop more cohesive and comprehensive educational programmes for dog owners, children and their parents. $^{66}$

\section{Prevention through supervision}

Close supervision of child-dog interactions by an adult who is both in close proximity and has been educated to interpret dog body language appropriately has a potential to prevent bites. ${ }^{58}$ However, a general lack of understanding that any dog can react aggressively towards any human under particular circumstances, hinders bite prevention. Compared with dog behaviour experts, dog-owning caregivers without expert knowledge of dog behaviour permit more high-risk interactions between children and both familiar and unfamiliar dogs (such as laying down in a dog's bed or taking a dog's bone away) and assess the risk of interactions as lower. ${ }^{46}$ The perception that one is not at risk around a familiar dog could help to explain why over $50 \%$ of caregivers leave children unattended around family dogs at least for a short period of time. ${ }^{46}$ Research into daily interactions between dogs and children under the age of 6 years revealed that most injuries occur in contexts other than agnostic aggression, such as when a child tried to give a dog a treat or while playing fetch. ${ }^{67}$ As most prevention programmes focus on recognising stress-related behaviours in dogs ${ }^{59}$ caregivers may not be aware of the context in which supervision of children around dogs is required. In addition, caregivers' exposure to an educational intervention aimed at preventing bites to children had no impact on their supervision behaviour. ${ }^{61}$ This suggests that caregivers' education into dog's body language should be supplemented with a campaign addressing both perceptions of contexts in which bites to children occur and commonly held views that 'a bite wouldn't happen to me' or 'my dog wouldn't bite'. ${ }^{18}$

\section{Prevention through environmental modification}

Given the difficulties in education and active supervision, bite prevention should include the promotion of environmental safety measures within the home. Compared with experts, caregivers rely on fewer methods of bite prevention and rarely use environmental controls. ${ }^{46}$ Environmental controls are less subject to human error and particularly useful in situations where strict supervision of the dog is difficult. Installation of baby gates and outside letterboxes, in addition to dog management, such as ensuring a dog cannot escape a property during visits by placing it in the back garden or a separate room, are potentially effective but underused approaches to preventing bites. ${ }^{57}$

Additionally, modification of dogs acquired by families, through socialisation, training and breeding of dogs less likely to bite (or cause serious damage when they do bite) should also be considered. Education of breeders and owners of the influence of biological inheritance, early-life experience and socialisation on human-directed aggression is important. ${ }^{2368}$ Social fearfulness has been associated with inadequate socialisation during puppyhood and inactivity in both training and play activities. ${ }^{69} 70$ Research suggests that small breeds are less often socialised and trained and are therefore more fearful of both strangers and other dogs compared with larger dogs, potentially increasing the risk of bites. ${ }^{69} 70$

Although dog bites most often occur in the owner's home, it is important to highlight that bites also occur within public areas. ${ }^{13}$ Prevention efforts must therefore extend to these spaces and consider additional factors such as dog on dog aggression which may also result in injury to humans. ${ }^{13}$ One strategy that has been used in North America is the implementation of 'leash laws' mandating owners to keep their dog on a lead within specific areas (see Rahim et al). ${ }^{71}$ In a cross-sectional survey of small animal veterinarians in the US, $79.9 \%$ endorsed stricter leash laws as a method to improve public safety compared with $6.1 \%$ for muzzling specific dog breeds in public. ${ }^{72}$ However, similar to dog fouling, the enforcement of dog leash laws is likely to be difficult, and also may have repercussions in terms of motivation for health-promoting physical activity in owners. ${ }^{73}$ Furthermore, public education of the appropriate behaviour of a child around an unfamiliar dog encountered in a public space is also essential, as they can still approach an on-leash dog. There is a lack of evidence of the efficacy of prevention strategies within public spaces and further research is needed. 


\section{Reducing bite impact and future incidents}

Although bites should be regarded as preventable injuries, mistakes will happen and therefore education should extend to what a child and caregiver should do during a dog bite incident in order to reduce injury severity, in addition to post-bite action such as psychological support. ${ }^{74}$ Following a bite, the owner should be helped to identify why the bite occurred, especially if a dog has not previously displayed aggressive behaviour. ${ }^{456}$ It is important that professional advice is given to the owner (from an expert animal behaviourist or veterinary surgeon with experience in dog behaviour) to ensure the dog can be safely managed. If the child is only exposed to the dog for short periods (as a visitor), or while the behaviours of a dog and the underlying reasons for it are being addressed, other context-specific risk management options include implementation of environmental barriers (such as baby gates) and pet training (such as crate or muzzle training). Ultimately, in cases where dog welfare is compromised and sufficient behaviour modification alongside risk management is not possible, rehoming of the animal (either temporarily, to allow time for the owner to reflect and consider the options available, or permanently) to a household that is able to manage the dog's behaviour may be considered (eg, if the aggression is focused on children, rehoming to an adult-only household may be feasible). In severe cases where an ongoing threat is posed, euthanasia should be considered. ${ }^{77}$

For parents considering introducing a dog into the home, there is a lack of robust evidence to help predict which breed or gender of dog is less likely to bite. ${ }^{23}$ Each dog should be considered on an individual basis with consideration given to temperament of the parents, previous socialisation, training and episodes of humandirected aggression. Parents should consider their home and how the dog would be managed alongside their children within that environment. In addition, they should consider the compatibility of their lifestyle with the potential requirements to promote the well-being of the dog (considering breed), including adequate training, and exercise.

\section{CONCLUSION}

There are many factors to consider when treating children with dog bite injuries. The psychological impact of these injuries for both the child and parent can be significant and is likely to be under-recognised. A multidisciplinary approach is required to both treat these patients and prevent bites from occurring in the first place.

Acknowledgements The author James A. Oxley's PhD studentship is funded by Dogs Trust. The author Sara C. Owczarczak-Garstecka is currently employed by Dogs Trust as a Research Officer, and her past PhD studentship was part-funded by Dogs Trust.

Contributors CW conceptualised the paper. MJ, JAO, SCO-G conducted the first draft. All authors commented on and revised the paper. CW submitted the paper.
Funding The author James A. Oxley's PhD studentship is currently funded by Dogs Trust.

Competing interests The author JAO's studentship is funded by Dogs Trust. The author SCO-G is currently employed by Dogs Trust as a Research Officer, and her past PhD studentship was part-funded by Dogs Trust. CW, SCO-G and JAO are members of the Merseyside Dog Safety Partnership, which has a website containing useful resources for dog bite prevention. www.merseydogsafe.co.uk.

Patient consent for publication Not required.

Provenance and peer review Commissioned; externally peer reviewed.

Data availability statement Data sharing not applicable as no datasets generated and/or analysed for this study. This is a review article and no datasets were generated or analysed for the study.

Open access This is an open access article distributed in accordance with the Creative Commons Attribution Non Commercial (CC BY-NC 4.0) license, which permits others to distribute, remix, adapt, build upon this work non-commercially, and license their derivative works on different terms, provided the original work is properly cited, appropriate credit is given, any changes made indicated, and the use is non-commercial. See: http://creativecommons.org/licenses/by-nc/4.0/.

ORCID iD

Carri Westgarth http://orcid.org/0000-0003-0471-2761

\section{REFERENCES}

1 Macpherson CN, Meslin FX, Wandeler Al. Dogs, zoonoses and public health. Wallingford, U.K: CABI Publishing, 2013.

2 World Health Organization. Animal Bites: Dog bites [online], 2018. Available: https://www.who.int/news-room/fact-sheets/detail/animalbites [Accessed Jun 2020].

3 Pet Food Manufacturers' Association. Dog population 2019 [online], 2019. Available: https://www.pfma.org.uk/dog-population-2019 [Accessed Mar 2020].

4 Digital NHS. Finished admission episodes and finished consultant episodes for accidents and dog bites, England, 2017-18 [online], 2018. Available: https://digital.nhs.uk/data-and-information/ find-data-and-publications/supplementary-information/2018supplementary-information-files/finished-admission-episodes-andfinished-consultant-episodes-for-accidents-and-dog-bites-england2017-18 [Accessed Mar 2020].

5 Loder RT. The demographics of dog bites in the United States. Heliyon 2019;5:e01360.

6 NHS Digital. Provisional Monthly HES for admitted patient care, outpatients and Accident and Emergency Data April 2014 to February 2015: Topic of interest: admissions caused by dogs and other mammals [online], 2015. Available: https://files.digital.nhs.uk/ pdf/h/6/animal_bites_m12_1415.pdf [Accessed Mar 2020].

7 Hall S, Dolling L, Bristow K, et al. Companion animal economics: the economic impact of companion animals in the UK. Wallingford, U.K.: CABI Publishing, 2016.

8 Gilchrist J, Sacks JJ, White D, et al. Dog bites: still a problem? Inj Prev 2008;14:296-301.

9 Fein J, Bogumil D, Upperman JS, et al. Pediatric dog bites: a population-based profile. Inj Prev 2019;25:290-4.

10 Mannion CJ, Graham A, Shepherd K, et al. Dog bites and maxillofacial surgery: what can we do? Br J Oral Maxillofac Surg 2015;53:522-5.

11 Reisner IR, Nance ML, Zeller JS, et al. Behavioural characteristics associated with dog bites to children presenting to an urban trauma centre. Inj Prev 2011;17:348-53.

12 Caffrey N, Rock M, Schmidtz O, et al. Insights about the epidemiology of dog bites in a Canadian City using a dog aggression scale and administrative data. Animals 2019;9:324.

13 Oxley JA, Christley R, Westgarth C. Contexts and consequences of dog bite incidents. J Vet Behav 2018;23:33-9.

14 Westgarth C, Brooke M, Christley RM. How many people have been bitten by dogs? A cross-sectional survey of prevalence, incidence and factors associated with dog bites in a UK community. $J$ Epidemiol Community Health 2018;72:331-6.

15 Boat BW, Dixon CA, Pearl E, et al. Pediatric dog bite victims: a need for a continuum of care. Clin Pediatr 2012;51:473-7.

16 Ji L, Xiaowei Z, Chuanlin W, et al. Investigation of posttraumatic stress disorder in children after animal-induced injury in China. Pediatrics 2010;126:e320-4.

17 Peters V, Sottiaux M, Appelboom J, et al. Posttraumatic stress disorder after dog bites in children. J Pediatr 2004;144:121-2. 
18 Westgarth C, Watkins F. Impact of dog aggression of victims. In: Mills DS, Westgarth C, eds. Dog bites: a multidisciplinary perspective. Sheffield, U.K: 5m Publishing, 2017: 309-20.

19 Shields LBE, Bernstein ML, Hunsaker JC, et al. Dog bite-related fatalities: a 15-year review of Kentucky medical examiner cases. Am J Forensic Med Pathol 2009;30:223-30.

20 The Committee on Trauma. Advanced trauma life support course manual. 10th edn. Chicago, IL, U.S.A: American College of Surgeons, 2018.

21 Mills DS, Demontigny-Bédard I, Gruen M, et al. Pain and problem behavior in cats and dogs. Animals 2020;10:318.

22 Guy NC, Luescher UA, Dohoo SE, et al. Risk factors for dog bites to owners in a general veterinary caseload. Appl Anim Behav Sci 2001;74:29-42.

23 Newman J, Christley RM, Westgarth C. Risk factors for dog bites-an epidemiological perspective. In: Mills DS, Westgarth C, eds. Dog bites: a multidisciplinary perspective. Sheffield, U.K: 5m Publishing, 2017: 133-58.

24 National Institute for Health and Care Excellence. Child maltreatment: when to suspect maltreatment in under $18 \mathrm{~s}$ [online], 2009. Available: http://www.nice.org.uk/guidance/cg89 [Accessed Mar 2020].

25 Elizabeth Murray G, Murray GE. Examining evidence on dog bite injuries and their management in children. Nurs Child Young People 2017;29:35-9.

26 Langguth P, Leissner L, Zick G, et al. Why Asplenic Patients Should Not Take Care of the Neighbour's Dog? A Fatal Course of Capnocytophaga canimorsus Sepsis. Case Rep Infect Dis 2018;2018:3870640.

27 Cook JA, Sasor SE, Soleimani T, et al. An epidemiological analysis of pediatric dog bite injuries over a decade. J Surg Res 2020;246:231-5.

28 National Institute for Health and Care Excellence. Bites - human and animal: Scenario: managing a dog or cat bite, 2018. Available: https://cks.nice.org.uk/bites-human-and-animal\#!scenario:1 [Accessed Mar 2020].

29 Rasmussen D, Landon A, Powell J, et al. Evaluating and treating mammalian bites. JAAPA 2017;30:32-6.

30 Public Health England. Guidelines on managing rabies postexposure October 2019, 2019. Available: https://assets.publishing service.gov.uk/government/uploads /system/uploads/attachment_ data/file/843148/PHE_guidelines_on_rabies_post-exposure_ treatment.pdf [Accessed Mar 2020].

31 Norman C, Stavisky J, Westgarth C. Importing rescue dogs into the UK: reasons, methods and welfare considerations. Vet Rec 2020;186:248.

32 Public Health England. Tetanus: the green book, chapter 30, 2019. Available: https://www.gov.uk/government/publications/tetanus-thegreen-book-chapter-30 [Accessed Mar 2020].

33 Medeiros I, Saconato H. Antibiotic prophylaxis for mammalian bites. Cochrane Database Syst Rev 2001;2:CD001738.

34 Cheng H-T, Hsu Y-C, Wu C-I. Does primary closure for dog bite wounds increase the incidence of wound infection? A meta-analysis of randomized controlled trials. J Plast Reconstr Aesthet Surg 2014;67:1448-50.

35 Paschos NK, Makris EA, Gantsos A, et al. Primary closure versus non-closure of dog bite wounds. A randomised controlled trial. Injury 2014;45:237-40.

36 De Keuster T, Lamoureux J, Kahn A. Epidemiology of dog bites: a Belgian experience of canine behaviour and public health concerns. Vet J 2006;172:482-7.

37 National Institute for Health and Care Excellence. Post-Traumatic stress disorder, 2018. Available: https://www.nice.org.uk/guidance/ ng116 [Accessed Mar 2020].

38 Meints K. Children and dogs- risk and effective dog bite prevention. In: Mills DS, Westgarth C, eds. Dog bites: a multidisciplinary perspective. Sheffield, U.K: $5 \mathrm{~m}$ Publishing, 2017: 390-401.

39 Beck AM, Jones BA. Unreported dog bites in children. Public Health Rep 1985;100:315.

40 Messam LLM, Kass PH, Chomel BB, et al. Factors associated with bites to a child from a dog living in the same home: a Bi-National comparison. Front Vet Sci 2018;5:66.

41 Monroy A, Behar P, Nagy M, et al. Head and neck dog bites in children. Otolaryngol Head Neck Surg 2009;140:354-7.

42 Schalamon J, Ainoedhofer $\mathrm{H}$, Singer G, et al. Analysis of dog bites in children who are younger than 17 years. Pediatrics 2006;117:e374-9.

43 Wei LA, Chen HH, Hink EM, et al. Pediatric facial fractures from dog bites. Ophthalmic Plast Reconstr Surg 2013;29:179-82.
44 Bernardo LM, Gardner MJ, O'Connor J, et al. Dog bites in children treated in a pediatric emergency department. J Spec Pediatr Nurs 2000;5:87-95.

45 Reisner IR, Shofer FS, Nance ML. Behavioral assessment of childdirected canine aggression. Inj Prev 2007;13:348-51.

46 Arhant C, Landenberger R, Beetz A, et al. Attitudes of caregivers to supervision of child-family dog interactions in children up to 6 years-An exploratory study. J Vet Behav 2016;14:10-16.

47 Messam LLM, Kass PH, Chomel BB, et al. Risk factors for dog bites occurring during and outside of play: are they different? Prev Vet Med 2012;107:110-20.

48 Owczarczak-Garstecka SC, Watkins F, Christley R, et al. Online videos indicate human and dog behaviour preceding dog bites and the context in which bites occur. Sci Rep 2018;8:7147.

49 Aldridge GL, Rose SE. Young children's interpretation of dogs' emotions and their intentions to approach happy, angry, and frightened dogs. Anthrozoös 2019;32:361-74.

50 Lakestani NN, Donaldson ML, Waran N. Interpretation of dog behavior by children and young adults. Anthrozoös 2014;27:65-80.

51 Ramgopal S, Bykowski MR, Chow I, et al. Weather patterns in the prediction of pediatric dog bites. Clin Pediatr 2019;58:354-7.

52 Webster CA, Farnworth MJ. Ability of the public to recognize dogs considered to be dangerous under the dangerous dogs act in the United Kingdom. J Appl Anim Welf Sci 2019;22:240-54.

53 Creedon N, Ó'Súilleabháin PS. Dog bite injuries to humans and the use of breed-specific legislation: a comparison of bites from legislated and non-legislated dog breeds. Ir Vet J 2017;70:23.

54 Yokoyama JS, Hamilton SP. Genetics of canine behavioural disorders. In: Ostrander E, Ruvinsky A, eds. The genetics of the dog. Wallingford, U.K: CABI Publishing, 2012: 275-94.

55 Sleet DA. The global challenge of child injury prevention. Int $J$ Environ Res Public Health 2018;15:1921.

56 Morrongiello BA, Schwebel DC. Introduction to special section: pediatric psychology and child unintentional injury prevention: current state and future directions for the field. J Pediatr Psychol 2017;42:721-6.

57 Shen J, Rouse J, Godbole M, et al. Systematic review: interventions to educate children about dog safety and prevent pediatric dog-bite injuries: a meta-analytic review. J Pediatr Psychol 2017;42:779-91.

58 Starling M, McGreevy P. Prevention of dog bites - resources and their value. In: Mills DS, Westgarth C, eds. Dog bites: a multidisciplinary perspective. Sheffield, U.K: $5 \mathrm{~m}$ Publishing, 2017: 381-90.

59 Shepherd K. Behavioural medicine as an integral part of veterinary practice. In: Horwitz D, Mills DS, eds. BSAVA manual of canine and feline behavioural medicine. Quedgeley, Gloucester, UK: BSAVA [British Small Animal Veterinary Association], 2009: 13-16.

60 Schwebel DC, Morrongiello BA, Davis AL, et al. The blue dog: evaluation of an interactive software program to teach young children how to interact safely with dogs. J Pediatr Psychol 2012;37:272-81.

61 Morrongiello BA, Schwebel DC, Stewart J, et al. Examining parents behaviors and supervision of their children in the presence of an unfamiliar dog: does the blue dog intervention improve parent practices? Accid Anal Prev 2013;54:108-13.

62 Hemenway D. While we were sleeping: success stories in injury and violence prevention. Oakland, CA, U.S.A: University of California Press, 2009.

63 Mohan D, Tiwari GN. Injury prevention and control. London,UK: CRC Press, 2000.

64 Hemenway D. Three common beliefs that are impediments to injury prevention. Inj Prev 2013;19:290-3.

65 Shumaker SA, Ockene JK, Riekert KA. The Handbook of health behavior change. 3rd edn. Springer Publishing, 2008.

66 Mannion CJ, Shepherd K. One health approach to dog bite prevention. Vet Rec 2014;174:151-2.

67 Arhant C, Beetz AM, Troxler J. Caregiver reports of interactions between children up to 6 years and their family Dog-Implications for dog bite prevention. Front Vet Sci 2017;4:130.

68 Á G-M, Martínez MF, Rosado B, et al. Association between puppy classes and adulthood behavior of the dog. J Vet Behav 2019;32:36-41.

69 Arhant C, Bubna-Littitz H, Bartels A, et al. Behaviour of smaller and larger dogs: effects of training methods, inconsistency of owner behaviour and level of engagement in activities with the dog. Appl Anim Behav Sci 2010;123:131-42.

70 Puurunen J, Hakanen E, Salonen MK, et al. Inadequate socialisation, inactivity, and urban living environment are associated with social fearfulness in PET dogs. Sci Rep 2020;10:1-10. 
71 Rahim T, Barrios PR, McKee G, et al. Public health considerations associated with the location and operation of off-leash dog Parks. $J$ Community Health 2018;43:433-40.

72 Kogan LR, Schoenfeld-Tacher RM, Hellyer PW, et al. Small Animal Veterinarians' Perceptions, Experiences, and Views of Common Dog Breeds, Dog Aggression, and Breed-Specific Laws in the United States. Int J Environ Res Public Health 2019;16:4081.

73 Westgarth C, Christley RM, Marvin G, et al. Functional and recreational dog walking practices in the UK. Health Promot Int 2020. doi:10.1093/heapro/daaa051

74 Mathews JR, Lattal KA. A behavioral analysis of dog bites to children. J Dev Behav Pediatr 1994;15:44-52.
75 Westgarth C, Watkins F. A qualitative investigation of the perceptions of female dog-bite victims and implications for the prevention of dog bites. J Vet Behav 2015;10:479-88.

76 Casey RA, Loftus B, Bolster C, et al. Human directed aggression in domestic dogs (Canis familiaris): occurrence in different contexts and risk factors. Appl Anim Behav Sci 2014;152:52-63.

77 Schalke E. Best advice to a dog owner whose dog has bitten someone. In: Mills DS, Westgarth C, eds. Dog bites: a multidisciplinary perspective. Sheffield, U.K: 5m Publishing, 2017: 343-9. 